\title{
Emission Norms (Case Study)
}

\author{
Monil Shah ${ }^{1}$, Chirag Mistry ${ }^{2}$, Naresh Shimpi ${ }^{3}$ \\ ${ }^{1,2}$ T.YAutomobile Engineering, Sardar Vallabhbhai Patel Polytechnic, I.C colony, link Road, Borivali (w), Mumbai-400103 \\ ${ }^{3}$ H.O.D. Automobile Engineering, Sardar Vallabhbhai Patel polytechnic, I.C colony, link Road, Borivali (w), Mumbai-400103
}

\begin{abstract}
Today emission has been one of the most dreaded words in this country. There have been a lot of problems in this country regarding emission. This emission problem is majorly caused due to automobile. Emission is caused due to exhaust of automobile which is caused due to unburnt hydrocarbons. In our country emission is a very big problem, despite there were many solutions created none of them are used in major scale. This paper analyses the various Bharat stage norms, disadvantages and appropriate solutions for emission and also explain the importance of proper emission.
\end{abstract}

Keywords: Emission, Bharat norms, Euro norms, Volkswagen, cheap solutions etc.

\section{Introduction}

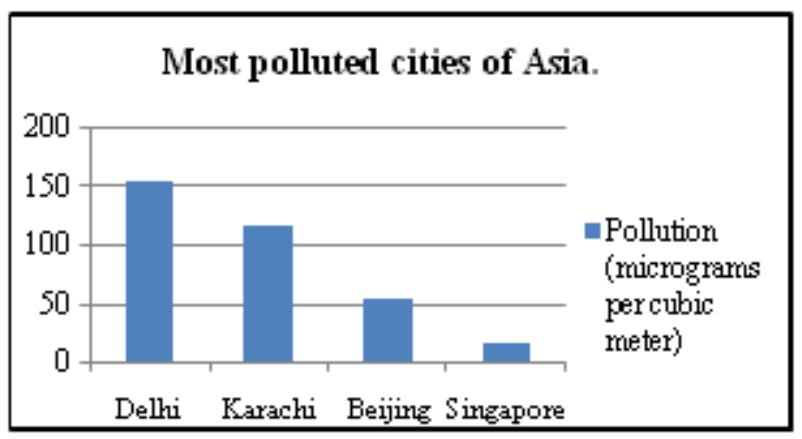

Figure 1: Most polluted cities of Asia.

The figure 1 shows the chart which shows the most polluted cities of ASIA Continent. Delhi ranks first in the most Air polluted city on the global level and it is true that Delhi has very rate of AIR POLLUTION.Emission is gas exiting to the atmosphere via a flue. Exhaust gas, flue gas generated by fuel. Combustion emission of greenhouse gases which absorb and emit radiation in thermal infrared range. The pollution in our country majorly in states like Delhi, Maharashtra is caused due to cars. Indian vehicles, per trip, produce 4 to 8 times more pollutants and consume more carbon foot prints, then free flowing cars. Due to this $50 \%$ of people are suffering from asthma and other respiratory disorders [1]. This leads to the acid rain which can cause skin diseases and in recent the marble of the great monument TAJ MAHAL is getting black spots because of the acid rain. If these emissions are not controlled then definitely it will affect to the human life very dangerously. [2] The AajTak news channel recently surveyed that the people living in Patna are badly suffering from respiratory disorders and they organized a medical camp to check the health of the nearbypeople, they found that $73.5 \%$ of the people has damaged lungs because of inhalation of the hydrocarbons, Nox, PM, and Co. due to this tar has settled in their lungs which is much equal to smoking 23 cigarettes on one time.

\section{Bharat Stage Norms}

These are the emission standard instituted by the government of India to regulate the output that is cause by the internal combustion engine, including the motor vehicle. The Indian stage norms are completely based on the European norms which were introduced in 2000 in INDIA. Progressively more stringent norms have been rolled out since then [1]. All new vehicles manufactured after this implementation of the norms have to be compliant with the regulation.

In 2010, Bharat stage III norms were implemented in the whole country. In 13 cities in April 2010 Bharat stage IV have been implemented. In 2016 India has decided to skip the Euro norm V and implement Euro norm VI by 2020.Figure 2 shows the advancement in BS -VI norms as compared to BS -III and BS -IV norms [4] [8] [10] .

Table 1: Petrol emission norm [4] [8] [10]

\begin{tabular}{|c|c|c|c|c|}
\hline \multicolumn{5}{|c|}{ Petrol Emission Norms (In g/Km) } \\
\hline Emission norm & $C O$ & $H C$ & NOx & $P M$ \\
\hline BS-III & 2.30 & 0.20 & 0.15 & - \\
\hline BS-IV & 1.00 & 0.10 & 0.08 & - \\
\hline Euro 6 & 1.00 & 0.10 & 0.06 & 0.00 \\
\hline
\end{tabular}

Table 2: Diesel emission norm [4] [8] [10]

\begin{tabular}{|c|c|c|c|c|}
\hline \multicolumn{5}{|c|}{ Diesel Emission Norms (In g/Km) } \\
\hline Emission norm & $C O$ & $H C$ & NOx & $P M$ \\
\hline BS-III & 0.64 & 0.50 & 0.56 & 0.05 \\
\hline BS-IV & 0.50 & 0.25 & 0.30 & 0.025 \\
\hline Euro 6 & 0.50 & 0.06 & 0.17 & 0.005 \\
\hline
\end{tabular}

\section{Disadvantages of Bharat Norms}

Since Bharat norms are completely influenced by the Euro norms so all the loop holes present in the euro norms are simply visible in the Bharat norms. [3] [4]There are many disadvantages of these norms. We have point out the major but the common disadvantages regarding the emission control plan. There are two main reasons for the harmful emission i.e.

1) Lack of maintenance

2) Leniencies in P.U.C.

And other more reasons like bad driving habits, sudden acceleration and sudden braking along with acceleration etc which leads to over fuel consumption.[6] 


\section{International Journal of Science and Research (IJSR) \\ ISSN (Online): 2319-7064}

Index Copernicus Value (2013): 6.14 | Impact Factor (2014): 5.611

\subsection{Lack of Maintenance}

In our country the major problems regarding emission is the Maintenance of their vehicle. We have given so much importance to passenger cars but nobody pays attention to the transport vehicles. The BEST busses that we use for transport are not maintained at all. Their engine create carbon footprint so they harm the environment to the greater extent[4]. The improper shifting of the gears can also lead to the greater fuel consumption. Some BEST drivers gives improper shift to the bus due to which sometime the bus gives black smoke during acceleration, and while starting. This clears that the engine of the buses are not properly maintained. They have carbon deposits inside the combustion chamber.

Due to this the fuel will not get completely burnt inside the combustion chamber and the un-burnt fuel will then pass to the exhaust and Nox is produced. These Nox then is inhaled by humans and causes respiratory disorders.

The similar case is with the Motorcycles and the Three Wheelers. More over the rickshaws that we travel in also produces a lot of carbon foot prints, because sometimes the auto rickshaw driver uses kerosene as alternate fuel to run their engines. Though their engine works but produces lots of black smoke which is more hazardous than the diesel soot's [4]. For the reason of the maintenance the 2stroke engines and the Maruti 800 car production has been stopped because it does not meets the emission norms and produces Co at very high rate.

In bikes the mixing of the oil and the fuel in case of two stroke engines also leads to burning of the oil inside the chamber due to which the fuel is wasted and smoke produced is also very much[3]. This damages the engine as well as the environment.

The figure 3 shows the graph of the four category of the vehicle i.e. cars, buses-trucks, Three wheeler, bikes, amongst these all which one is maintained very much of these all.[3]

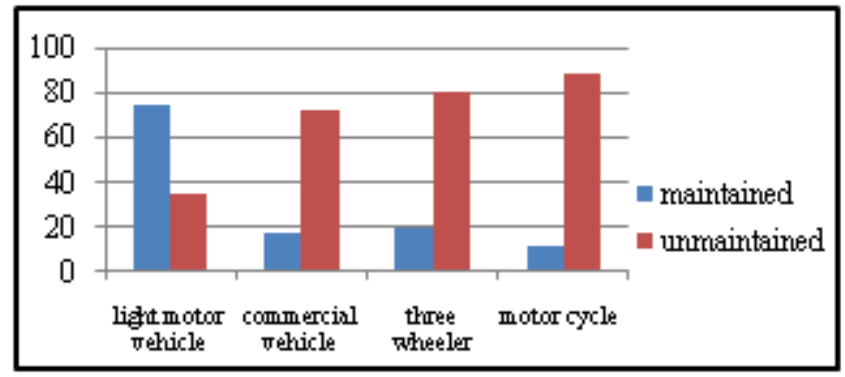

Figure 2: Comparison between maintained and unmaintained vehicle [3]

The mostly maintained vehicle amongst all these category is the Light Motor Vehicle (CAR). Because there are lots of cars owned by the owner. [4] [6]

\subsection{Leniencies in P.U.C}

The other reason for the harmful emission is the P.U.C. A recent survey shows that every 6 out of 10 vehicles in Madhya Pradesh donot have their P.U.C.registered.Even in Bombay in certain areas there are cars which do have a P.U.C. There are so many P.U.C. vendors to catch hold he people to check weather their vehicle is not emitting smoke beyond the norm limit. After checking they only suggest the vehicle ownerthat"Sir please service your vehicle" rather than renewing the vehicles P.U.C. and without taking their vehicle owner in custody and charging them the FINE. These peoples are left because they bribe the P.U.C. vendors. people in our country when their take bikes they change their silencers and use straight baffle due to which the "catalytic converter" the device used to make chemical changes in the exhaust of the combustion is removed so the straight flow of gas leads to direct emission of $\mathrm{NOx}, \mathrm{Co}, \mathrm{HC}$ etc into the air. .[4] [7]

We have made a survey and selected four major cities of INDIA i.e. Delhi, Mumbai, Bihar, West Bengal. We found out the ratios of number of vehicle which have their P.U.C. done and who all have not registered their P.U.C. yet.

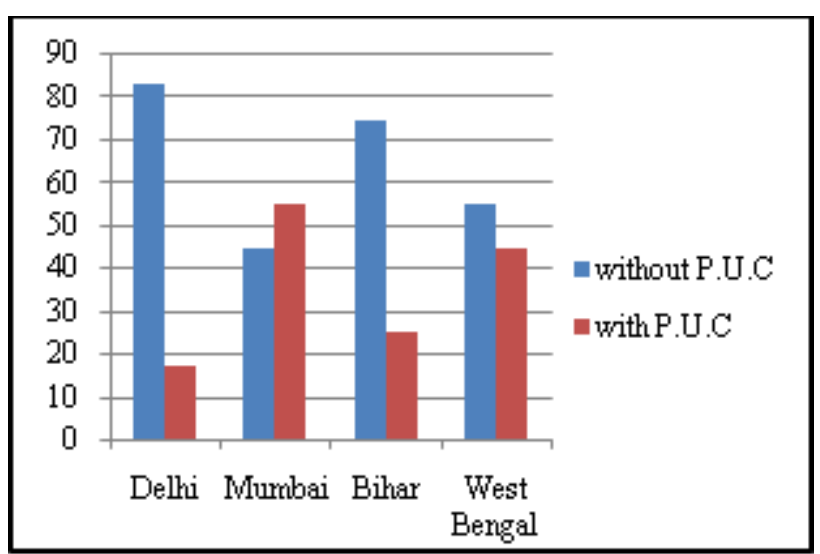

Figure 3: Comparison of P.U.C. and non P.U.C. vehicle

The highest ratio is seen in the Delhi where the vehicles have not registered their P.U.C.[10]

\subsection{The Volkswagen Incident}

This incident is considered to be one of the biggest frauds in the history of the automobile engineering. This scandal was also said to be the diesel dupe scandal. In September the Environment Protection Agency found that many VW cars sold in America had a CHEATING DEVICE in diesel engine that could detect when they were being tested, changing the performance accordingly to improve results. They admitted their mistake in America. This device sounded like a sophisticated kit which could sense when the car is at testing and by monitoring speed, operation, air pressure and even position of steering wheel and due to this it emitted 40 times above what it was allowed. Due to this they had to face a lot of financial loss. They had a loss of 6.7 billion EUROS in its first quarter and 2.7 billion EUROS in 2 quarter. It had called 8.5 million cars from EUROPE including 2.5 million from Germany and 


\section{International Journal of Science and Research (IJSR) \\ ISSN (Online): 2319-7064}

Index Copernicus Value (2013): 6.14 | Impact Factor (2014): 5.611

1.2million cars from London. They had to face a total loss of 18 billion.[5] [9].

\section{Solution}

\subsection{Government Involvement}

The government should actively participate in this issue and rather than finding temporary solutions he should look for some permanent solution.

The best example is of the Even Odd policy currently started by Hon. C.M. (Delhi) MR. ARVIND KEJRIVAL. At Delhi in order to bring the emission rate in control.

Result of this policy:- There has been temporary drop seen in the rate of emission but the vast change has not been seen. This is the first step in emission reduction and the government is also trying best to make the emission rate less which is required by the emission norms.

\subsection{Use of Emission Reducing Devices}

Devices like CATALYTIC CONVERTOR, EXHAUST GAS RECIRCULATION system should be used to reduce the emission.

(a) Catalytic Converter: The device which is used to make chemical changes in the exhaust emission so that it becomes less harmful when exposed to the open environment. It filters the $90 \%$ of liquid matter from the Diesel exhaust.[4]

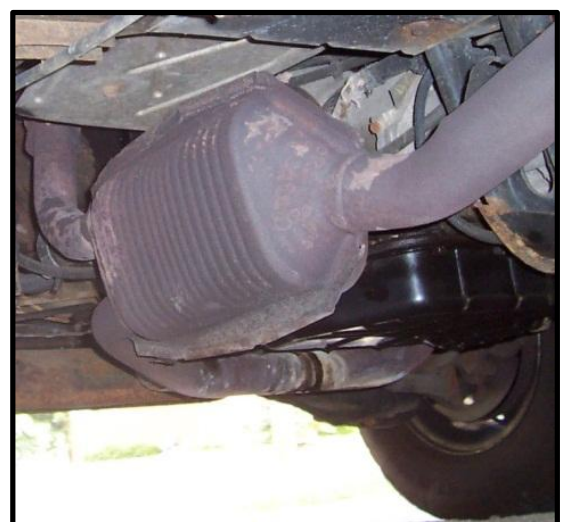

Figure 5: Catalytic converter

(b) Exhaust Gas Recirculation System:-The device used to recirculate the unburntfuel which pass out in the exhaust and again mixes less than $10 \%$ of unburnt fuel in the intake manifold. The main aim of the EGR system is to reduce NOx production.[4]

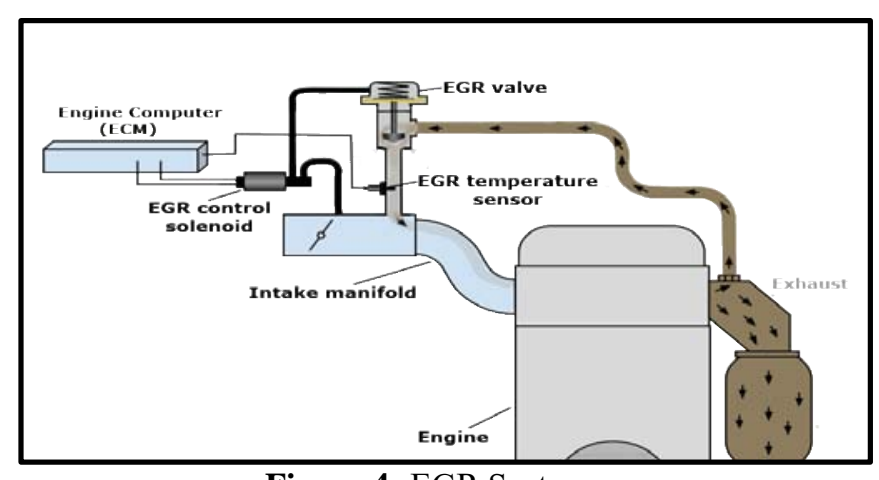

Figure 4: EGR System

\subsection{Strict Rules}

There should be more strictness in the rules so that unnecessary emission producing vehicle should beimmediately taken in the custody to check the emission level and the action to be taken accordingly.modification is avoided.

\subsection{Timely Maintenance}

Timely maintenance is necessary to avoid the carbon deposition in the combustion chamber which effect the complete combustion of the fuel.

\subsection{Replacing Fuel Filter Timely}

Change the fuel filter timely, because if the fuel is not filtered properly then the contaminated fuel will be supplied to engine which defects the combustion process.

\section{Few Tips}

Do not use straight baffle mufflers since it removes the catalytic converter which is the base of reducing pollution.

Turn off the lights of the vehicle during night when the vehicle is in heavy traffic since it uses battery power to run the lights as well as to provide spark for the combustion. It will produce more amount of unburnt fuel, since the battery takes the load and does not provide required voltage to efficient spark for the complete combustion.

Neglect all the extra showoff accessories which use the power from the battery to work. If the vehicle is full from this show off accessories then it will consume large current from the battery and combustion will not be efficient. So more NOx, Co, Hc will beproduced.

\section{Future}

This graph shows the appropriate future after using this solution 


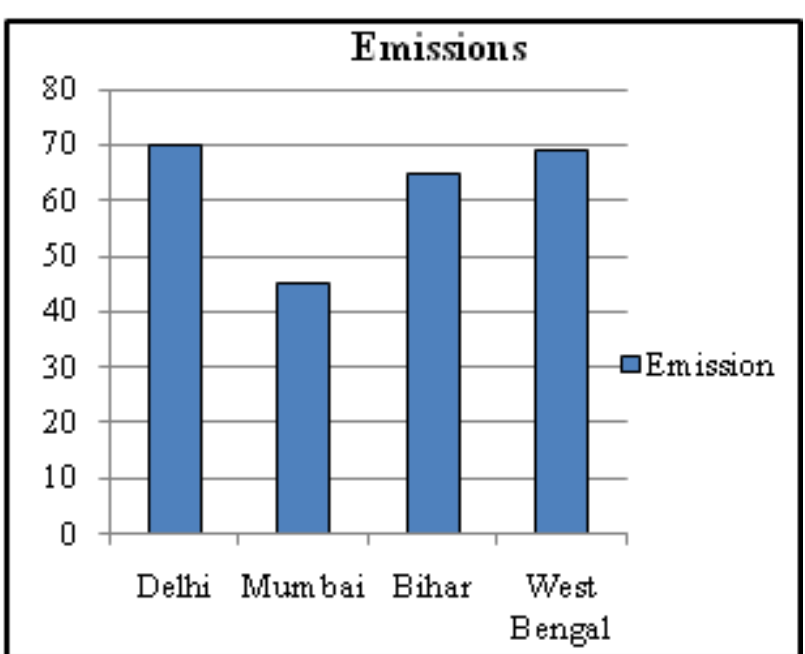

Figure 5: Future

\section{Conclusion}

This topic was basically selected to make you all aware where we stand despite of having some of talent andmoney. India is considered to be a country where primary industry is the largest markets, we are considered to be a country where we support the slogans "Go Green" and on the other hand our few citizens pollute our country. Let us do our bit by making people aware about this issue and reduce the rate of deaths by applying this following measure. Even if 30\% people start taking this issue seriously then the deaths caused by the pollution can reduce by $10 \%$ annually. We can go for HYBRID VEHICLES or vehicles which are running on alternating energy source, but in country like India to afford such vehicles is very difficult since some of the population is below poverty line and most of the population is middle class.

So the measures which we have given by us can be preferred by all the classes of people in India.

\section{References}

[1] www.wikkipedia.com

[2] www.aajtak.com

[3] www.carthrottle.com

[4] www.teambhp.com

[5] Volkswagen - scandal / article 7681778 THE HINDU $23^{\text {rd }}$ September 2015.

[6] "India switches fully to Euro III and IV petrol and diesel" The Hindu. 24 September 2010

[7] "straightdrive" BHPlan /Team BHP News $/ 20^{\text {th }}$ November 2009.

[8] United states Environmental protection agency (October 22, 1998) Mack trucks diesel engine settlement.

[9] www.djindexes.com/mdsidx/html/tandc/indexestandc s.html. S\&P index data is the property of Chicago mercantile Exchange inc. and its licensors.

[10]"Functions of the central pollution control Board" central pollution control Board 